\title{
Eudaimonic Growth: Narrative Growth Goals Predict Increases in Ego Development and Subjective Well-Being 3 Years Later
}

\author{
Jack J. Bauer \\ University of Dayton
}

\author{
Dan P. McAdams \\ Northwestern University
}

\begin{abstract}
We examine (a) the normative course of eudaimonic well-being in emerging adulthood and (b) whether people's narratives of major life goals might prospectively predict eudaimonic growth 3 years later. We define eudaimonic growth as longitudinal increases in eudaimonic well-being, which we define as the combination of psychosocial maturity and subjective well-being (SWB). College freshmen and seniors took measures of ego development (ED; to assess maturity; Loevinger, 1976) and SWB at Time 1 (T1) and again 3 years later (Time 2). ED levels increased longitudinally across that time for men and T1 freshmen, but SWB levels did not change. Participants also wrote narratives of 2 major life goals at T1 that were coded for an explicit emphasis on specific kinds of personal growth. Participants' intellectualgrowth goals (especially agentic ones) predicted increases in ED 3 years later, whereas participants' socioemotional-growth goals (especially communal ones) predicted increases in SWB 3 years later. These findings were independent of the effects of Big Five personality traits-notably conscientiousness, which on its own predicted increases in SWB. We discuss (a) emerging adulthood as the last stop for normative eudaimonic growth in modern society and (b) empirical and theoretical issues surrounding the relations among narrative identity, life planning, dispositional traits, eudaimonia, and 2 paths of personal growth.
\end{abstract}

Keywords: growth goals, eudaimonic well-being, ego development, narrative, traits

Do people's goals for personal growth actually predict selfdevelopment years later? The belief that they do is certainly widespread, if self-help book sales and the American ideal of the self-made individual are any indication (Korda, 2001; de Tocqueville, 1840/1988). Yet research has demonstrated little direct relation between personal goals and personally meaningful selfdevelopment over time.

To study "actual" self-development, we turned to measures of eudaimonic well-being over time. The terms eudaimonia and eudaimonic well-being refer broadly to human flourishing. Qualities of eudaimonia often represent what people want most in life (Flanagan, 2007; King \& Napa, 1998). Although specific definitions of eudaimonia vary, they all involve something in addition to hedonic happiness, such as meaning in life, prosocial growth, intrinsic motivation, vitality, wisdom, or psychosocial maturity (Bauer, McAdams, \& Pals, 2008; King \& Hicks, 2007; Ryan, Huta, \& Deci, 2008; Ryff \& Singer, 2008; Waterman, Schwartz, \& Conti, 2008). Research on eudaimonic well-being has blossomed in recent years, but typically not within prospective, developmental frameworks (Deci \& Ryan, 2008; Kashdan, Biswas-Diener, \& King, 2008; Ryan \& Deci, 2001). Here we define eudaimonic

Jack J. Bauer, Department of Psychology, University of Dayton; Dan P. McAdams, Foley Center for the Study of Lives, Northwestern University.

This research was supported by a grant from the Foley Family Foundation. We wish to thank Mary Anne Machado, Matt Montoya, Sun Park, Douglas Robinett, and April Sakaeda.

Correspondence concerning this article should be addressed to Jack J. Bauer, Department of Psychology, University of Dayton, Dayton, OH 45469. E-mail: jack.bauer@udayton.edu growth operationally as increases in eudaimonic well-being over time. We examine normative patterns of eudaimonic growth as well as whether growth goals (i.e., goals aiming for personal growth; Bauer \& McAdams, 2004a) predict individual differences in eudaimonic growth.

\section{Eudaimonic Growth}

We define eudaimonic growth as increases in psychosocial maturity and subjective well-being (SWB) over time. This definition derives from our definition of eudaimonic well-being (at any one point in time) as high levels of both psychosocial maturity and SWB (e.g., Bauer et al., 2008; Bauer, McAdams, \& Sakaeda, 2005b; see also King \& Hicks, 2007). This view of eudaimonic well-being considers not only how good one feels about one's life (i.e., SWB) but also how complexly and integratively one thinks about one's life (i.e., psychosocial maturity). To measure maturity in this sense of the term, we used Loevinger's measure of ego development (ED; Hy \& Loevinger, 1996). Higher levels of ED involve greater capacities for perspective taking, less defensiveness, and other qualities of psychosocial maturity (Bauer, 2008). ${ }^{1}$ As it turns out, maturity and SWB function as relatively distinct

\footnotetext{
${ }^{1}$ However, we think other frameworks of eudaimonic well-being are important to pursue from a developmental perspective. For example, Ryff \& Singer (1998) presented cross-sectional data on eudaimonic well-being from younger to older adulthood. They defined eudaimonic well-being in the sense of what we have called "meaningfulness" (Bauer et al., 2008) - a sense of satisfaction with different sources of meaning in one's life, rather than in the sense of SWB plus integrative complexity in thinking about the self and others.
} 
facets of personality. Measures of ED typically do not correlate with measures of SWB, which deal with how good one feels about the self and others (e.g., Bauer \& McAdams, 2004a, 2004b; King \& Smith, 2004; Pals, 2006b). Similarly, ED and SWB show different patterns of life-course development.

\section{The Course and Potentially Peaking Period of ED}

ED for individuals in contemporary, industrialized nations tends to increase throughout childhood and adolescence and into the early 20s, but not consistently beyond that period (Cohn, 1998; Labouvie-Vief, 2006; Westenberg \& Gjerde, 1999). The normative stage of ED for adults (the self-aware stage; see Method section) is unlikely to emerge before late adolescence, and the next stage (conscientious) is unlikely to surface before emerging adulthood (Loevinger, 1993). ED levels appear to remain relatively stable throughout much of adulthood (Cohn, 1998). So it seems that emerging adulthood (Arnett, 2000) serves as the last period in which substantial gains in ED are expectable-that after this point, society leaves individuals more or less on their own to cultivate more complex, integrative understandings of their psychosocial lives. Whether the last normative gains occur in just the earlier ("college years") or also the later period (the mid-20s) of emerging adulthood is not clear.

\section{The Flat Path of SWB}

In contrast to maturity, systematic changes in SWB appear not to be normative during emerging adulthood or at any period in the life span (Diener, Lucas, \& Scollon, 2006), except perhaps for slightly higher levels in older adulthood (Mroczek \& Kolarz, 1998). Individuals may have a set point for SWB, around which SWB rises and falls over time but to which SWB eventually returns, except in a minority of cases (Diener et al., 2006). In the current study, we measure SWB in its widely studied form, that is, the combination of life satisfaction and positive and (inversely) negative affect (e.g., Oishi, Diener, \& Lucas, 2007).

\section{Hypothesis 1: Normative Eudaimonic Growth in Emerging Adulthood}

First, we propose that the term eudaimonic growth has stronger and weaker definitions. The strong definition involves increases in both ED and SWB. Defined strongly, eudaimonic growth appears not to be normative at any period in the life course. Defined weakly, eudaimonic growth involves increases in ED while at least maintaining previous levels of SWB, such that one's "sum total" of ED and SWB increases. (An increase in SWB while maintaining previous levels of ED would merely be an increase in hedonic well-being, not in eudaimonic well-being.) Adopting the weaker definition of eudaimonic growth, our first hypothesis is that eudaimonic growth is normative in emerging adulthood. Our sample (see Method) allows us to compare earlier versus later years of emerging adulthood.

\section{Personal Growth? Goals as Predictors of Eudaimonic Growth}

We are especially interested in personal goals as a predictor of future eudaimonic growth. If personal growth is at all possible, then research should be able to demonstrate that goals for personal growth - that is, growth goals (Bauer \& McAdams, 2004a) predict the attainment of personally desirable forms of growth. To the degree that eudaimonic well-being represents desirable life conditions (culturally speaking, at least), then having growth goals for one's major life goals should predict eudaimonic growth.

Yet no study to our knowledge has shown a direct, prospective relation between goals or traits and increases in both ED and SWB. Still, some studies of goals and possible selves have come close. In a 2-year longitudinal study, gay and lesbian participants provided narratives of their either gay or lesbian and straight "best possible selves" (King \& Smith, 2004). Greater conceptual elaboration of straight best possible selves predicted increases in ED 2 years later. However, measures of possible selves did not predict increases in life satisfaction (a component of SWB; Diener et al., 2006). A longitudinal study of college students over the course of one academic year showed that self-concordant (i.e., self-determined) goals predicted goal attainment, which in turn predicted increases in both maturity (measured as Eriksonian identity achievement) and adjustment to college, but initial goals alone did not predict these increases (Sheldon \& Houser-Marko, 2001). Similar findings emerged in one-semester, longitudinal studies (Sheldon \& Elliot, 1999; Sheldon, Kasser, Smith, \& Share, 2002). Thus, we find no study to have demonstrated how personal goals directly predict increases in well-being, let alone both well-being and maturity, over a considerable period.

\section{Narrative Growth Goals}

The present study features narratives of people's major life goals. Narratives are a medium through which people construct meaning in their lives (McAdams, 2006). The development of personal narratives over time is in many ways at the heart of self-development (i.e., the development of self-identity over time; McLean, Pasupathi, \& Pals, 2007). By studying narratives of major life goals, we aimed to study people's intentional efforts to guide that self-development in a personally meaningful direction. Narratives of major life goals reveal not only what people want most in life but also the reasons for those goals-including reasons that underlie or predominate among a set of personal desires and worries. We coded goal narratives for two kinds of personal growth-intellectual and socioemotional - that could take agentic or communal orientations (based on Bauer \& McAdams, 2004a, 2004b).

\section{Intellectual- and Socioemotional-Growth Goals}

Intellectual-growth goals emphasize growth in how one thinks, whereas socioemotional-growth goals emphasize growth in how one feels and acts. Intellectual-growth goals emphasize the importance of heightening one's knowledge (or fostering others' knowledge), pursuing conceptual exploration and learning, and understanding the self and others better, but not necessarily a more deeply felt experience of those things. In contrast, socioemotionalgrowth goals emphasize a deepening or strengthening in the felt experience of one's psychosocial life, but not explicitly a deeper conceptual understanding of it. Socioemotional-growth goals involve aims for a deepening of life experience, greater vitality (i.e., "feeling alive"), building personally meaningful skills, cultivating 
personally meaningful relationships, and making contributions to society and future generations. The operational definition of socioemotional-growth goals is based largely on self-determination theory (Deci \& Ryan, 2000; Kasser \& Ryan, 1993), though with the narrative's explicit emphasis on growth. ${ }^{2}$

\section{Agentic and Communal Growth}

Intellectual- and socioemotional-growth goals can each be oriented toward either agentic or communal growth, or both (Bauer \& McAdams, 2004b; see also McAdams, Hoffman, Mansfield, \& Day, 1996). Whereas intellectual and socioemotional growth deal with the roughly thinking and feeling facets of self-development, agentic and communal growth deal with the roughly intrapersonal and interpersonal facets of self-development. See Figure 1 for a schematic summary of the different growth goals and the Appendix for examples.

\section{Growth Goals and Eudaimonic Well-Being}

Past research has shown that intellectual-growth narratives (particularly agentic ones) correlate with ED, whereas socioemotionalgrowth narratives (particularly communal ones) correlate with SWB (Bauer \& McAdams, 2004a, 2004b; Bauer, McAdams, \& Sakaeda, 2005a). In a cross-sectional analysis that suggests eudaimonic growth, older adults scored higher than young adults on eudaimonic well-being, but these ties to age were mediated by growth goals (Bauer \& McAdams, 2004a). Whether growth goals predicted prospective increases in ED or SWB remained to be seen.

\section{Hypothesis 2: Growth Goals Predict Eudaimonic Growth}

Our second hypothesis for the present study is that growth goals predict individual differences in eudaimonic growth (in the strong

\begin{tabular}{|c|c|c|}
\hline & $\begin{array}{l}\text { AGENTIC } \\
\text { GROWTH }\end{array}$ & $\begin{array}{l}\text { COMMUNAL } \\
\text { GROWTH }\end{array}$ \\
\hline $\begin{array}{l}\text { INTELLECTUAL } \\
\text { GROWTH }\end{array}$ & $\begin{array}{l}\text { Goals aiming for: } \\
\text { - heightened conceptual } \\
\text { knowledge of self } \\
\text { - conceptual exploration } \\
\text { and learning for the sake } \\
\text { of one's own knowledge }\end{array}$ & $\begin{array}{l}\text { Goals aiming for: } \\
\text { - heightened conceptual } \\
\text { knowledge of others } \\
\text { \& relationships } \\
\text { - fostering others' } \\
\text { intellectual development }\end{array}$ \\
\hline $\begin{array}{l}\text { SOCIOEMOTIONAL } \\
\text { GROWTH }\end{array}$ & $\begin{array}{l}\text { Goals aiming for: } \\
\text { - deeper experience of } \\
\text { self and one's own } \\
\text { actions and events } \\
\text { - strengthening of } \\
\text { personally meaningful } \\
\text { abilities }\end{array}$ & $\begin{array}{l}\text { Goals aiming for: } \\
\text { - deeper experience of } \\
\text { others and relationships } \\
\text { - greater abilities to act } \\
\text { fairly or caringly } \\
\text { - fostering others' growth }\end{array}$ \\
\hline
\end{tabular}

Figure 1. Themes of growth goals: Whereas intellectual- and socioemotional-growth goals deal with the roughly thinking and feeling facets of self-development, agentic and communal growth goals deal with the roughly intrapersonal and interpersonal facets of self-development. definition). More precisely, we predicted that intellectual-growth goals (especially agentic ones) would predict increases in ED but not SWB, whereas socioemotional-growth goals (especially communal ones) would predict increases in SWB but not ED.

\section{Personality Traits}

The Big Five personality traits-neuroticism, extraversion, openness to experience, conscientiousness, and agreeablenessrepresent the most widely studied model of individual differences. Moreover, the Big Five traits are often considered to be the basic building blocks of personality, with personality characteristics such as goals and narratives being mere epiphenomena (e.g., McCrae \& Costa, 1999). Yet narratives consistently predict indices of psychological health and well-being beyond the effects of broad personality traits (Bauer \& McAdams, 2004b; Bauer et al., 2005a, 2005b; McLean \& Pratt, 2006; Roberts, O’Donnell, \& Robins, 2004), even longitudinally (Lodi-Smith, Geise, Roberts, \& Robins, 2009). In an extension of Hypothesis 2, we expected that narrative growth goals would be independent of broad personality traits in predicting facets of eudaimonic growth.

\section{Method}

\section{Participants}

Participants were college freshmen and seniors from Northwestern University, a highly competitive, private school near Chicago. The first measurement time, Time 1 (T1), involved 145 participants. Another measurement time, Time 2 (T2), occurred approximately 3.5 years later and involved 87 of the original participants $(60 \%)$ who provided data for the primary measures. At T1, the freshmen were approximately 18 years old $(M=18.1, S D=0.30$; range: $18-19)$ and the seniors were approximately $21(M=20.9$, $S D=0.60$; range: $20-22$ ). Thus at $\mathrm{T} 2$ the $\mathrm{T} 1$ freshmen were approximately 21 , and the T1 seniors were approximately 24 . Ages were almost the same for those who stayed in the study as for those who dropped out. As for cohort, T1 had 64 freshmen (44\%) and 81 seniors, whereas T2 had $40 \mathrm{~T} 1$ freshmen (46\%) and $47 \mathrm{~T} 1$ seniors. Gender was disproportionately female, though common for studies of this type: At T1, 107 participants (74\%) were female, whereas at T2, 68 participants (78\%) were female. Ethnicity was distributed as follows: At T1 (and at T2), 70\% (76\%) of the students indicated European American, 19\% (18\%) indicated Asian American, 5\% (2\%) indicated African American, 2\% (2\%) indicated Hispanic, and 5\% (1\%) indicated "other." Participants who dropped out of the study did not differ from participants who remained in the study in terms of the T1 measures of ED, SWB, and growth goals. We did not gather information about languages spoken in the home or family socioeconomic status.

\section{Procedure}

In the fall semester of the 1 st year of data collection, we recruited participants via flyers, advertisements in the campus

\footnotetext{
${ }^{2}$ In past research we used the terms exploratory and intrinsic growth goals, but these terms were inaccurate in various ways. Intellectual and socioemotional were chosen to demonstrate a relative difference in the thinking-versus-feeling emphasis in concerns for personal growth.
} 
newspaper, and sign-up tables in the student union. Students who expressed interest in participating were given a booklet of questionnaires to complete at their leisure and were asked to return the booklet in person or via campus mail within 2 weeks. The booklet took $3-5 \mathrm{hr}$ to complete. Students who were given a survey but who did not return it within 3 weeks were contacted by phone or e-mail for encouragement to complete the survey. Participants took the survey again approximately 3 years later in the fall semester, by which time almost all the $\mathrm{T} 1$ freshmen had become seniors and the T1 seniors were almost 3 years out of college. Participants were paid $\$ 50$ each time they completed the survey. Participants received the same survey at each measurement time. The survey included an open-ended question about major life goals, sentencecompletion tasks to measure psychosocial maturity, and Likerttype measures of well-being and Big Five personality traits. For a study on autobiographical memories and other phenomena that also came from this project, see McAdams et al. (2006).

\section{Measures of Growth Goals}

Participants were asked to describe, in two paragraphs, two of their major life goals. After being told to think about their life's future in a broad sense and about their major life goals, participants were instructed,

You may have many goals, but please choose the two that seem the most important to you right now and describe each to us below. Please write a paragraph for each goal that explains what the goal is and how you are trying to or plan to achieve it.

Narratives were then coded according to an established protocol that was made more stringent for the current study (Bauer \& McAdams, 2004a, 2004b).

Overview of coding the goal narratives. Coders first identified what the goal was about behaviorally or objectively (e.g., success in love or work, to obtain something like a career or a marriage or financial security). These types of goals were not the primary focus of the coding. Any one of these types of goals could be coded in various ways. Rather, the target element of the narrative was the participant's predominant reason (or reasons) for having that major life goal. We have found in other research that the explicitly stated, subjective reasons or motivations for goals are stronger predictors of personality and well-being measures than are the behavioral types of goals (Bauer et al., 2005a). Sometimes the reasons for goals were made explicit in causal statements such as "I want to join the circus because ...,", but more often the reasons emerged in words or phrases that conveyed the personal importance of the goal or by outlining one's strategy for implementing the goal. Examples appear in the Appendix, but here is a quick excerpt: "I want to create art that causes people to think in new ways." This expresses a goal type ("I want to create art"), but the phrase "that causes people to think in new ways" endows the goal with a personally meaningful purpose. It is important to note that narratives typically reveal competing motivations or reasons for having a goal, yet any one narrative can be coded as reflecting predominantly one versus the other-a matter of emphasis (Bauer $\&$ McAdams, 2004b). The particular reasons of concern for this study dealt most broadly with growth rather than safety (Maslow, 1968). More specifically, each major life goal was coded for the presence or absence of two kinds of growth: intellectual and socioemotional. Two researchers (the first author and an advanced graduate student) coded each major life goal, were blind to participants' scores on other measures, and attained reasonable levels of interrater reliability (intellectual-growth goals, $\kappa=.80$, and socioemotional-growth goals, $\kappa=.69$ ). Discrepancies were resolved by discussion. Examples of growth goals appear in the Appendix.

Coding for intellectual-growth goals. Each goal was coded in a dichotomous fashion for the presence or absence of an explicit concern for intellectual growth. The presence of an intellectualgrowth goal was coded when the reason for the goal was explicitly to integrate, explore, learn, investigate, or encounter new, conceptual perspectives or conceptual challenges. The absence of an intellectual-growth goal involved a desire to experience or obtain something, without an explicit concern for intellectual or conceptual growth. We note that intellectual-growth and non-intellectualgrowth goals were measured as two sides of the dichotomous variable "intellectual-growth goals." Finally, the intellectual growth that is intended in a goal may be one's own or someone else's (see Coding for agentic and communal growth).

Coding for socioemotional-growth goals. Each goal was also coded in a dichotomous fashion for the presence or absence of socioemotional growth. The presence of a socioemotional-growth goal was coded when the reason for the goal was explicitly to foster some form of personal growth such as improving a personality characteristic (but not intellectual growth), experiencing life more fully (along the lines of vitality), the growth of a specific meaningful relationship, or contributions to society or future generations. A non-socioemotional-growth goal involved (a) extrinsically motivated reasons for having the goal (e.g., wanting to gain money, status, or approval; Sheldon \& Kasser, 1995); (b) reasons explicitly dealing with progress or improvement, even if dealing with humanistic things such as relationships; (c) wanting to overcome an unpleasant deficit rather than to develop something for the intrinsic love of the thing itself (e.g., wanting to recover or improve one's health to get back to "normal," rather than for the intrinsic enjoyment or self-identified value of doing the kinds of things that lead to good health); or (d) wanting to preserve or maintain one's present conditions. We note the distinction between goal types and goal reasons described earlier. For example, the goal of "making enough money" could be coded as a socioemotional-growth goal if the reasons for making money were to provide an education for one's children, but not if the reasons were grounded in gaining fame and prestige (which is less about growth than about hedonic self-image). We note that the socioemotional-growth goals and non-socioemotional-growth goals were measured as two sides of the dichotomous variable "socioemotional-growth goals." As with intellectual-growth goals, socioemotional-growth goals could be agentic or communal.

Coding for agentic and communal growth. Growth goals were also coded for the psychosocial orientations of agency and communion. A single goal could emphasize both agentic and communal growth. Figure 1 provides an overview of criteria for coding agentic and communal orientations of both intellectual and socioemotional growth. Interrater reliability was .82 for agency and .86 for communion.

Computing variables of growth goals. Because each person described two goals, each person could have zero, one, or two intellectual-growth goals as well as zero, one, or two 
socioemotional-growth goals. Past research has shown that almost all intellectual-growth narratives are also coded as socioemotionalgrowth narratives (e.g., Bauer \& McAdams, 2004a). In other words, most growth narratives deal with some form of socioemotional growth. To distinguish intellectual from socioemotional growth, we recoded any goal that was coded for intellectual and socioemotional growth into the variable for intellectual-growth goals (but not socioemotional growth). Thus the resulting growthgoal variables differentiated goals that explicitly emphasized intellectual growth from goals that explicitly emphasized socioemotional growth exclusively.

\section{Other Measures}

Ego development. The Washington University Sentence Completion Test of Ego Development (Hy \& Loevinger, 1996) asks participants to complete 18 sentence stems (e.g., "When a child will not join in group activities ...," "A man's job ...,", "My mother and I . . ," "A wife should ...," "Rules are ..."). Each item is scored according to guidelines, aggregated for each participant, and assigned a total protocol rating. The total protocol rating scores correspond to different levels or stages of ED. Starting at Level 2 (with Level 1 being reserved for the presocial infant who as yet lacks an ego), the total protocol rating scores are $2=$ impulsive (passively dependent), 3 = self-protective (opportunistic), 4 = conformist (following rules), 5 = self-aware (fairness, consideration of rules), 6 = conscientious (self-evaluated standards), 7 = individualistic (respect for others' standards), $8=$ autonomous (understanding of interdependence), and $9=$ integrated (reconciles conflicts within a broader identity). An advanced graduate student coded the responses after months of training in the theory and measurement of ED and after establishing an agreement rate with practice materials (Hy \& Loevinger, 1996) of greater than $85 \%$. The ED scoring guidelines, which are self-instructive, have shown high levels of reliability and internal consistency (Loevinger, 1976).

Subjective well-being. SWB was measured as an aggregate of life satisfaction, positive affect, and (inversely scored) negative affect (see Diener et al., 2006). Participants completed the Satisfaction With Life Scale (Diener, Emmons, Larson, \& Griffen, 1985). This scale is a well-validated, simple five-item measure of overall life satisfaction. Items include "I am satisfied with the current state of affairs in my life" and "If I could live my life over, I would change almost nothing." Items are rated on a scale of 1 (strongly disagree) to 7 (strongly agree). Participants also completed the Positive and Negative Affect Schedule (Watson, Clark,
\& Tellegen, 1988). The Positive and Negative Affect Schedule has two subscales, one for positive affect and one for negative affect. Participants rated "to what extent" $(1=$ very slightly or not at all to $5=$ extremely) they generally experience each of 20 emotions -10 positive and 10 negative. Scores for life satisfaction and the Positive and Negative Affect Schedule were standardized and aggregated (with negative affect scores subtracted) to form a measure of SWB representing self-reports of both affective experience and general appraisals of life satisfaction.

Traits. The Big Five Inventory (John \& Srivastava, 1999) is a well-validated measure in which participants rate on a 5-point scale the degree to which each of 44 items describes one's own personality. The prompt reads, "I see myself as someone who. ..." Sample descriptions include "can be tense," "is outgoing, sociable," and "is curious about many different things." Items converge on five personality traits: neuroticism, extraversion, openness, conscientiousness, and agreeableness.

\section{Results}

\section{Descriptive and Demographic Statistics}

Frequencies of growth goals appear in Table 1. Participants were more likely to have socioemotional-growth goals than intellectual-growth goals, $\chi^{2}(86)=7.73, p=.021$, as found in previous research (Bauer \& McAdams, 2004a). In other words, goals aiming primarily toward a deepening of experience were more common than goals focused on conceptual learning. Highly skewed distributions of all forms of growth goals led us to collapse them into presence-absence variables. These dichotomous variables were used in the statistical analyses that follow.

\section{Change and Stability in ED and SWB}

Two ways to measure personality change over time with continuous-level data are mean-level comparisons and rank-order correlations (see Caspi, Roberts, \& Shiner, 2005).

Mean levels of ED. For the sample as a whole, ED increased significantly (see Table 2). However, both gender and cohort played a role. Women had higher levels of ED than men at Time $1\left(\mathrm{ED}_{1}\right)$, but not at Time $2\left(\mathrm{ED}_{2}\right)$. In a repeated-measures analysis of variance, gender and time of measure interacted significantly, $F(1,85)=4.72, p=.033, \eta_{\mathrm{p}}^{2}=.05, B=0.50,95 \%$ CI $[0.05$, 0.95], such that men increased in ED more than women (see Figure 2). Women's mean levels of ED did not increase significantly. As for cohort, T1 freshmen did show a significant increase in ED,

Table 1

Frequencies of Growth Goals at Time $1(N=87)$

\begin{tabular}{|c|c|c|c|c|c|c|}
\hline \multirow[b]{2}{*}{ Theme } & \multicolumn{2}{|c|}{0} & \multicolumn{2}{|c|}{1} & \multicolumn{2}{|c|}{2} \\
\hline & $n$ & $\%$ & $n$ & $\%$ & $n$ & $\%$ \\
\hline Intellectual & 54 & 62 & 31 & 36 & 2 & 2 \\
\hline Agentic intellectual & 55 & 63 & 30 & 34 & 2 & 2 \\
\hline Communal intellectual & 72 & 83 & 15 & 17 & 0 & 0 \\
\hline Socioemotional & 36 & 41 & 40 & 46 & 11 & 13 \\
\hline Agentic socioemotional & 51 & 59 & 34 & 39 & 2 & 2 \\
\hline Communal socioemotional & 40 & 46 & 42 & 48 & 5 & 6 \\
\hline
\end{tabular}


Table 2

Ego Development (ED) at Times 1 and 2

\begin{tabular}{|c|c|c|c|c|c|c|c|c|c|c|}
\hline \multirow[b]{2}{*}{ Sample } & \multicolumn{2}{|c|}{$\mathrm{ED}_{1}$} & \multicolumn{2}{|c|}{$\mathrm{ED}_{2}$} & \multirow[b]{2}{*}{$t$} & \multirow[b]{2}{*}{$d f$} & \multirow[b]{2}{*}{$p$} & \multirow[b]{2}{*}{$\eta_{\mathrm{p}}^{2}$} & \multicolumn{2}{|c|}{ T1 95\% CI } \\
\hline & $M$ & $S D$ & $M$ & $S D$ & & & & & $L L$ & $U L$ \\
\hline Women & $5.87^{\mathrm{a}}$ & 0.84 & 6.04 & 1.12 & 1.33 & 67 & .187 & .03 & 5.56 & 6.07 \\
\hline Men & $5.37^{\mathrm{a}}$ & 0.96 & 6.21 & 1.18 & 2.51 & 18 & .022 & .26 & 4.91 & 5.83 \\
\hline $\mathrm{T} 1$ freshmen & 5.75 & 1.01 & 6.27 & 1.01 & 2.68 & 39 & .011 & .16 & 5.43 & 6.08 \\
\hline $\mathrm{T} 1$ seniors & 5.77 & 0.79 & 5.92 & 1.12 & 0.88 & 46 & .384 & .02 & 5.54 & 6.00 \\
\hline Total & 5.76 & 0.89 & 6.08 & 1.13 & 2.49 & 86 & .015 & .07 & 5.57 & 5.95 \\
\hline
\end{tabular}

Note. All $t$ tests are simple paired samples except where noted. Independent samples statistics are noted only where significant. Interaction statistics (Gender $\times$ Time, Cohort $\times$ Time) are reported in the text. T1 $=$ Time $1 ; \mathrm{CI}=$ confidence interval; $L L=$ lower limit; $U L=$ upper limit.

${ }^{\mathrm{a}}$ Independent samples, $t(85)=-2.21, p=.030, M_{\text {diff }}=0.50,95 \%$ CI $[.05, .94], \eta_{\mathrm{p}}^{2}=.05$.

whereas T1 seniors did not (see Table 2). However, a repeatedmeasures analysis of variance showed that cohort and time of measure did not interact significantly, $F(1,85)=2.13, p=.148$, $\eta_{\mathrm{p}}^{2}=.02$. The three-way interaction of Gender $\times$ Cohort $\times$ Time was also not significant.

Mean levels of SWB. SWB at T1 $(M=0.07, S D=2.22)$ and $\mathrm{T} 2$ $(M=0.00, S D=2.26)$ were not significantly different for the sample as a whole. In other words, SWB levels stayed the same. Interactions of neither Gender $\times$ Time nor Cohort $\times$ Time were significant.

Rank-order stability in ED and SWB. $\mathrm{ED}_{1}$ correlated significantly with $\mathrm{ED}_{2}$. $\mathrm{SWB}_{1}$ correlated significantly with $\mathrm{SWB}_{2}$ (see Table 3). In other words, for both ED and SWB, participants who scored relatively high or low on that measure at $\mathrm{T} 1$ were also likely to do so at T2, demonstrating rank-order stability in both ED and SWB.

\section{Correlations Among Growth Goals, Traits, and Eudaimonic Growth}

Intellectual-growth goals. Intellectual-growth goals correlated significantly with $\mathrm{ED}_{1}$ and $\mathrm{ED}_{2}$ (see Table 3). This was especially the case for agentic intellectual-growth goals, compared

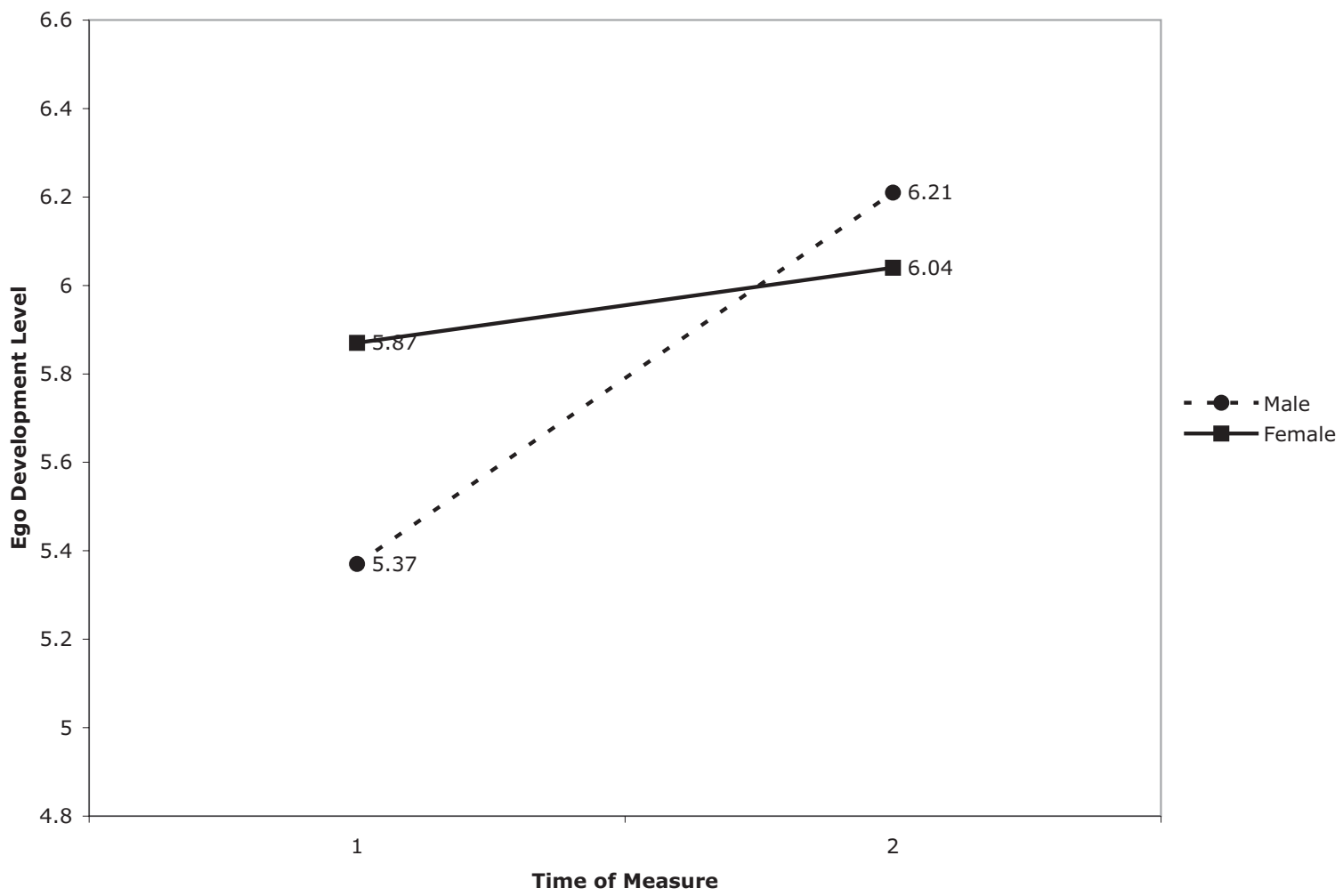

Figure 2. Gender and increases in ego development (ED): The sample as a whole showed an increase in ED from Time 1 to Time 2 ( 3 years later), but men were more likely than women to show an increase. Women had higher levels of ED than men at Time 1, but levels were statistically equivalent at Time 2. See Table 2 for comparisons of means. 
Table 3

Correlations Among Growth Goals, Ego Development, Subjective Well-Being, and Traits

\begin{tabular}{|c|c|c|c|c|c|c|c|c|c|c|c|c|c|c|c|}
\hline Variable & $\mathrm{ED}_{1}$ & $\mathrm{ED}_{2}$ & $\mathrm{SWB}_{1}$ & $\mathrm{SWB}_{2}$ & IGG & AIGG & CIGG & SGG & ASGG & CSGG & $\mathrm{N}$ & E & $\mathrm{O}$ & $\mathrm{C}$ & A \\
\hline $\mathrm{ED}_{1}$ & - & & & & & & & & & & & & & & \\
\hline $\mathrm{ED}_{2}$ & $.31^{* *}$ & - & & & & & & & & & & & & & \\
\hline $\mathrm{SWB}_{1}$ & $.22^{*}$ & .17 & - & & & & & & & & & & & & \\
\hline $\mathrm{SWB}_{2}$ & .02 & .00 & $.50^{* * * *}$ & - & & & & & & & & & & & \\
\hline IGG & $.32^{* *}$ & $.39^{* * * * *}$ & .18 & -.03 & - & & & & & & & & & & \\
\hline AIGG & $.32^{* * *}$ & $.41^{* * * * *}$ & .17 & -.06 & $.98^{* * * *}$ & - & & & & & & & & & \\
\hline CIGG & $.26^{*}$ & $.21^{*}$ & .17 & -.06 & $.58^{* * * * *}$ & $.54^{* * * * *}$ & - & & & & & & & & \\
\hline SGG & .12 & -.09 & $.22^{*}$ & $.42 * * *$ & -.18 & -.19 & .05 & - & & & & & & & \\
\hline ASGG & .18 & .10 & $.21^{*}$ & $.40^{* * * * *}$ & $.24^{*}$ & $.21^{*}$ & $.28^{* * *}$ & $.69^{* * * *}$ & - & & & & & & \\
\hline CSGG & .11 & -.04 & $.21^{*}$ & $.47^{* * * * *}$ & -.05 & -.07 & .20 & $.81^{* * * *}$ & $.51^{* * * * *}$ & - & & & & & \\
\hline $\mathrm{N}(\mathrm{T} 1)$ & -.15 & -.17 & $-.52^{* * * *}$ & $-.27^{*}$ & -.16 & -.13 & -.11 & -.11 & -.13 & -.14 & - & & & & \\
\hline $\mathrm{E}(\mathrm{T} 1)$ & .18 & .12 & $.47^{* * * * *}$ & $.30^{* *}$ & .09 & .10 & .05 & .11 & .18 & .06 & -.13 & - & & & \\
\hline $\mathrm{O}(\mathrm{T} 1)$ & .15 & .19 & $.22^{*}$ & .11 & .20 & .18 & $.21^{*}$ & .08 & .11 & .02 & -.14 & $.23^{* * *}$ & - & & \\
\hline $\mathrm{C}(\mathrm{T} 1)$ & .09 & .12 & $.32^{* *}$ & $.42^{* * * *}$ & -.10 & -.13 & .00 & $.31^{* * *}$ & $.24^{*}$ & $.39^{* * * *}$ & -.14 & .10 & -.06 & - & \\
\hline $\mathrm{A}(\mathrm{T} 1)$ & .20 & .15 & $.23^{*}$ & .08 & -.11 & -.11 & -.04 & $.30^{*}$ & .14 & $.28^{* *}$ & $-.24^{* *}$ & $.21^{*}$ & .19 & $.25^{*}$ & - \\
\hline
\end{tabular}

Note. $\mathrm{ED}_{1}, \mathrm{ED}_{2}=$ ego development level at Time $1(\mathrm{~T} 1)$ and Time $2(\mathrm{~T} 2) ; \mathrm{SWB}_{1}, \mathrm{SWB}_{2}=$ subjective well-being at $\mathrm{T} 1$ and $\mathrm{T} 2 ; \mathrm{IGG}=$ intellectual-growth goals; AIGG = agentic intellectual-growth goals; $\mathrm{CIGG}=$ communal intellectual-growth goals; $\mathrm{SGG}=$ socioemotional-growth goals; $\mathrm{ASGG}=$ agentic socioemotional-growth goals; $\mathrm{CSGG}=$ communal socioemotional-growth goals; $\mathrm{N}=$ neuroticism; $\mathrm{E}=$ extraversion; $\mathrm{O}=$ openness; $\mathrm{C}=$ conscientious; $\mathrm{A}=$ agreeableness.

${ }^{*} p<.05 .{ }^{* * *} p<.01{ }^{* * * *} p<.001$.

with communal intellectual-growth goals (see regression below). Intellectual-growth goals did not correlate significantly with either $\mathrm{SWB}_{1}$ or $\mathrm{SWB}_{2}$. Pearson correlations are presented in the table for the sake of comparison, but $t$ tests-more appropriate with the dichotomized variable of intellectual-growth goals-showed the same levels of significance.

Socioemotional-growth goals. Socioemotional-growth goals correlated significantly with $\mathrm{SWB}_{1}$ and $\mathrm{SWB}_{2}$, but not with $\mathrm{ED}_{1}$ or $\mathrm{ED}_{2}$. Agentic and communal socioemotional-growth goals correlated with SWB similarly (we expected communal growth goals to correlate more strongly; see regressions below).

Traits. No trait except conscientiousness at $\mathrm{T} 1$ correlated significantly with both $\mathrm{SWB}_{1}$ and $\mathrm{SWB}_{2}$ as well as with growth goals (notably, socioemotional-growth goals, both agentic and communal; see Table 3). These relations laid the foundation for a test of mediation (Baron \& Kenny, 1986).

\section{Regressions: Predicting Increases in ED and SWB}

The regression models in this section tested whether individual differences in growth goals and traits would account for changes in ED and SWB over time. Neither gender nor cohort affected these findings, so regression models involve the sample as a whole.

Intellectual-growth goals. When we regressed $\mathrm{ED}_{2}$ on $\mathrm{ED}_{1}$ and then added intellectual-growth goals, $\mathrm{ED}_{1}$ predicted $\mathrm{ED}_{2}$ marginally significantly $(\beta=.21, p=.051, B=0.26,95 \%$ CI $[0.00$, 0.53 ], initial $\left.R_{\text {adj }}^{2}=.084\right)$, and intellectual-growth goals predicted $\mathrm{ED}_{2}$ significantly $(\beta=.32, p=.003, B=0.74,95 \%$ CI $[0.26$, 1.22 ], $\left.\Delta R_{\mathrm{adj}}^{2}=.083\right)$. Thus intellectual-growth goals predicted significant increases in ED. This was especially the case for agentic intellectual-growth goals. In a regression of ED change that compared agentic and communal intellectual-growth goals, $\mathrm{ED}_{1}$ predicted $\mathrm{ED}_{2}$ marginally significantly, $\mathrm{ED}_{1}(\beta=.20, p=$ $.057, B=0.25,95 \%$ CI $[-0.01,0.51]$, initial $\left.R_{\text {adj }}^{2}=.084\right)$ and agentic intellectual-growth goals predicted $\mathrm{ED}_{2}$ significantly $(\beta=$ $.35, p=.001, B=0.81,95 \%$ CI $\left.[0.34,1.30], \Delta R_{\text {adj }}^{2}=.101\right)$, but communal intellectual-growth goals did not significantly predict increases in ED.

Socioemotional-growth goals. In a regression of $\mathrm{SWB}_{2}$, both $\mathrm{SWB}_{1}(\beta=.43, p=.000, B=0.45,95 \% \mathrm{CI}[0.26,0.64]$, initial $\left.R_{\text {adj }}^{2}=.24\right)$ and socioemotional-growth goals $(\beta=.32, p=.001$, $\left.B=1.77,95 \% \mathrm{CI}[0.78,2.77], \Delta R_{\text {adj }}^{2}=.10\right)$ predicted $\mathrm{SWB}_{2}$ significantly. Next we compared agentic and communal orientations of socioemotional-growth goals in predicting increases in SWB. In a simultaneous regression, $\mathrm{SWB}_{1}$ predicted $\mathrm{SWB}_{2}$ significantly $(\beta=.40, p=.000)$, as did communal socioemotionalgrowth goals $(\beta=.30, p=.003)$, but agentic socioemotionalgrowth goals no longer did so $(\beta=.18, p=.071)$. We note that agentic socioemotional-growth goals alone significantly predicted increases in SWB $(\beta=.31, p=.001)$, but that its drop in $\beta$ to .18 (when considering communal socioemotional-growth goals in the model) was significant (Sobel $z=3.29, p=.001$ ). Thus communal socioemotional-growth goals partially mediated the relation between agentic socioemotional-growth goals and increases in SWB, according to standard guidelines (Baron \& Kenny, 1986).

Growth goals and traits. Conscientiousness was the only Big Five trait that predicted increases in SWB, and no trait predicted increases in ED. In a regression of $\mathrm{SWB}_{2}, \mathrm{SWB}_{1}(\beta=.41, p=$ $.000, B=0.43,95 \%$ CI $[0.23,0.63]$, initial $\left.R_{\text {adj }}^{2}=.24\right)$ and conscientiousness $(\beta=.29, p=.003, B=1.28,95 \%$ CI $[0.44$, 2.11], $\Delta R_{\mathrm{adj}}^{2}=.07$ ) independently predicted $\mathrm{SWB}_{2}$. We then regressed $\mathrm{SWB}_{2}$ on $\mathrm{SWB}_{1}$ first, conscientiousness second, and communal socioemotional-growth goals third: $\mathrm{SWB}_{1}$ predicted $\mathrm{SWB}_{2}$ significantly $(\beta=.38, p=.000, B=0.40,95 \%$ CI $[0.21$, $0.59])$, conscientiousness did so marginally $(\beta=.17, p=.077$, $B=0.76,95 \%$ CI $[-0.08,1.59])$, and communal socioemotionalgrowth goals did so significantly $(\beta=.32, p=.001, B=1.74$, $95 \%$ CI $\left.[0.76,2.73], \Delta R_{\text {adj }}^{2}=.09\right)$. Conscientiousness' drop in $\beta$ from .26 to .17 was significant (Sobel $z=2.92, p=.002$ ). Thus communal socioemotional-growth goals partially mediated the relation between conscientiousness and increases in SWB. 


\section{Discussion}

This study aimed to investigate normative patterns and personality predictors of eudaimonic growth during emerging adulthood. Eudaimonic growth was defined as increases in ED and SWB. The overall findings can be summarized in two parts. First, eudaimonic growth was found normatively for men but not women and for participants across the college years but not for participants in the years after college. Second, participants with more growth goals were likely to show eudaimonic growth 3 years later, controlling for broad personality traits. Furthermore, specific kinds of growth goals pointed down two distinct component paths of eudaimonic growth, namely ED and SWB. These findings have implications for understanding the societal and individual factors in the course of eudaimonic growth, the role of narrative self-identity in eudaimonic growth, and the scientific study of personal growth.

\section{The Normative Path of Eudaimonic Well-Being Emerging Adulthood}

As predicted, ED and SWB followed different courses over time. Maturity levels (measured as ED) increased overall, although this varied by gender and cohort. In contrast, SWB levels did not change significantly over the 3 years, consonant with life-span research on SWB (Diener et al., 2006).

Gender and cohort. As for gender differences in ED, men started at T1 with lower levels than women but showed a greater increase in ED over the course of 3 years, such that men had caught up by T2. As for cohort, T1 freshmen showed gains in ED 3 years later, whereas T1 seniors did not. These findings support past research showing that men catch up to women in ED by the early 20s (Bursik, 1995; Westenberg \& Gjerde, 1999), that gender is generally not a factor after that point (Bauer \& McAdams, 2004a, 2004b; Bursik \& Martin, 2006; see also integrative complexity, Truluck \& Courtenay, 2002), and that psychosocial maturity peaks normatively at about that time (see also Cohn, 1998; Labouvie-Vief, 2006). The present findings suggest that the cresting and plateau of maturity may be found in the earlier and later periods, respectively, of emerging adulthood.

Social environments and eudaimonic growth. Why might have eudaimonic growth been found in the earlier but not the later period of emerging adulthood? We suspect that the reason deals with the different social environments of the two cohorts at T2. The $\mathrm{T} 1$ freshmen were still in college at $\mathrm{T} 2$ and thus in an environment that provides systematic training on (and an ethos of) thinking from multiple perspectives. In contrast, by T2 most of the T1 seniors had been out of college for almost 3 years. Social environments outside college vary widely in how much they foster personal development, but it seems reasonable to suggest that they are not on average as likely as college environments to hold the individual's learning as their primary purpose.

Emerging adulthood as a normative peak. Emerging adulthood, spanning the ages of roughly 18 to the mid-20s or even later, is a period of life-span development that has recently emerged in largely industrialized cultures (Arnett, 2000). The period is in many ways an extension of Erikson's (1968) adolescent period of identity versus role confusion. The historical emergence of a period of emerging adulthood, Arnett (2000) argues, is a reflection of the cultural need to give individuals more time to establish a sense of personal identity before taking on a full range of adult responsibilities in an increasingly complex society (e.g., higher education, global information). In terms of ED, society appears to scaffold its individuals to the self-aware stage, somewhere between conformist thinking and self-evaluated standards (Loevinger, 1976). At some point in the period of emerging adulthood (our data say after the college years, at least for those who go to college), individuals seem to be on their own when it comes to cultivating eudaimonic growth.

\section{Narrative Growth Goals as Predictors of Eudaimonic Growth}

Broadly speaking, we found that participants who planned their lives around personal growth demonstrated eudaimonic growth 3 years later. Furthermore, growth goals differentiated the two facets of eudaimonic growth.

Intellectual- and socioemotional-growth goals. Participants who planned for a life of conceptual exploration and learning (i.e., intellectual growth) were likely to show increases in ED (but not SWB) 3 years later. In contrast, participants who planned for a life of deepening their experience of life, deepening relationships, and contributing to society (i.e., socioemotional growth) were likely to show increases in SWB (but not ED) 3 years later. As mentioned earlier, we know of only one longitudinal study in which goalrelated constructs prospectively predicted increases in maturity (King \& Smith, 2004) and no study in which personal goals prospectively predicted increases in well-being directly. The present study demonstrated that a framework of growth goals could prospectively predict and differentiate two facets of eudaimonic growth, that is, psychosocial maturity and SWB.

Agency and communion. Agentic and communal orientations further differentiated these relations. Agentic (but not communal) intellectual-growth goals predicted increases in ED, whereas communal (but not agentic) socioemotional-growth goals predicted increases in SWB. A similar pattern has been found in narrative studies (Bauer \& McAdams, 2004b; King \& Noelle, 2005) and may be rooted in the facts that agentic motives have stronger ties to differentiation (i.e., complexity) in psychosocial contexts (Woike, Lavezzary, \& Barsky, 2001), whereas communal motives have stronger ties to well-being (Baumeister \& Leary, 1995; McAdams, 1988).

Goals and traits: What one wants to be versus what one is. Growth goals played a considerably larger role than Big Five traits did in predicting increases in ED and SWB over time. Only conscientiousness predicted increases in SWB, yet communal socioemotional-growth goals partially mediated that relation. Contrary to the building-block assumption that traits drive other aspects of personality such as personal goals and narratives (McCrae \& Costa, 1999), the present findings suggest that movement toward eudaimonia is more proximally a function of subjective, personal goals than Big Five traits. Furthermore, traits showed little overall relation to growth goals. Altogether, these findings contribute to the mounting evidence that narratives are not merely derivatives of traits (Bauer \& McAdams, 2004b; Bauer et al., 2005a, 2005b; Lodi-Smith et al., 2009; Roberts et al., 2004; see also McAdams \& Pals, 2006). In other words, one cannot infer a person's life story and identity from his or her broad personality traits (McAdams, 1995), particularly in terms of how the life story 
relates to psychosocial maturity and SWB. Eudaimonic growth was predicted more by what participants subjectively wanted to become than by what they already were-at least as portrayed by broad personality traits.

On the prevalence of growth goals. Approximately twice as many participants had socioemotional-growth goals as had intellectual-growth goals. This is similar to past research on growth narratives - in the United States as well as in Japan (Bauer \& McAdams, 2004a, 2005b; Bauer et al., 2005b; Kamide \& Daibo, 2008). So it seems that a majority of people organize narrative memories and goals around some notion of growth (even in old age; Bauer \& Park, in press), but only a minority of people explicitly name intellectual growth as a central source of meaning when interpreting and planning a life.

\section{Implications: Growth, Narratives, and Eudaimonia}

This study drew from a wide range of research and theory: personal goals, narrative self-identity, self-determination theory, SWB, eudaimonic well-being, and psychosocial and socialcognitive development. Plus the study compared the desire for growth with the attainment of growth. Here we try to sort through some of the present study's potential contributions to these areas.

Defining personal growth. The phenomenon of personal growth is often defined without much precision, even in scientific psychology. Growth can mean anything from a mere gain to an organismic, progressive process (Bauer \& Park, in press). We hope that the construct of growth goals can contribute ideas and methods toward a more differentiated, empirical study of personal growth. Toward this aim, we start with the idea that personal growth has both subjective and objective components- essentially a subjective desire for personal development and an objective attainment of personality development. But things quickly get more complex. Empirical research demands that the subjective desire for growth be studied objectively. In addition, the objective measure of personality development often involves subjective construals of self and others. Each measure in the present study had both subjective and objective dimensions to it. We used relatively objective assessments of participants' subjective desires for personal growth (i.e., growth goals) to predict objective increases (via partialing out the overlapping statistical variance of measures at $\mathrm{T} 1$ and T2) in SWB levels and in the relatively objective, structural complexity of subjective thoughts about the self and others (i.e., ED). With these methods we found that (a) different forms of personal growth (intellectual and socioemotional, with agentic and communal orientations) can be systematically identified and (b) goals for personal growth predicted objective assessments of eudaimonic growth. Perhaps most importantly, we found that specific kinds of growth goals pointed down different paths of personality development. In other words, "growth" is not a diffuse, catch-all category that means simply "positive things happen." Indeed, growth goals predicted eudaimonic well-being prospectively, even controlling for positivity and negativity (whether measured directly as affect or by proxy as extraversion and neuroticism). Participants thought about personal growth in specific ways that predicted specific paths of their own development.

Narrative self-identity and two ideas of growth. Past research has shown that individuals can be taught to think with greater psychosocial maturity (Manners, Durkin, \& Durkin, 2004) and that individuals' actions (though not goals) can directly predict increases in well-being (Lyubomirsky, Sheldon, \& Schkade, 2005; Sheldon \& Lyubomirsky, 2006). The present study demonstrated that merely planning and thinking about one's life in terms of growth-not whether goals were implemented or attainedprospectively predicted eudaimonic growth 3 years later. We think narrative analysis was key to this. Whereas narratives generally reflect key processes of self-development (McLean et al., 2007), growth themes in narratives reflect a personal identification with the idea of growth, such that the concept of self-development itself is revealed as the key source of personal value to the individual (Bauer, 2008; Bauer et al., 2008). Elements of intellectual-growth goals have been studied in narrative research as causal connections between events and the self (Pals, 2006a), autobiographical reasoning (Pasupathi \& Mansour, 2006), lessons and insights about the self (McLean, 2005), meaning-making (McLean \& Pratt, 2006), elaboration-detail (King \& Smith, 2004), accommodation (King, Scollon, Ramsey, \& Williams, 2000), concerns for selftransformation (Pals, 2006b), wisdom (Bluck \& Gluck, 2004), and identity integration (Bauer et al., 2005b; Blagov \& Singer, 2004). Elements of socioemotional-growth goals include happy endings (King et al., 2000), coherent positive resolution (Pals, 2006b), matching between possible and actual selves (King \& Raspin, 2004; King \& Smith, 2004), and intrinsic motivation (Bauer \& McAdams, 2004b; Bauer et al., 2005b), but these constructs alone still seem to require an explicit emphasis on growth before they will predict increases in SWB prospectively. Growth themes in narratives involve such an explicit emphasis.

Balancing the two facets of eudaimonic growth. We wish to emphasize that eudaimonic growth incorporates two empirically distinct paths of personality development. In other words, eudaimonic growth as we define it is a matter of balancing the intellectual with the socioemotional-the examined life with pleasure, wisdom with compassion, the head with the heart (Bauer, 2008). This study demonstrated that people who could balance concerns for both intellectual and socioemotional growth in their major life goals could expect a balanced growth consisting of two unrelated but important facets of human development.

\section{Conclusion}

In this article we aimed to present a framework for studying eudaimonic well-being from a developmental perspective by introducing the concept of eudaimonic growth. We hope this study generates interest in how people intentionally plan their lives in ways that might lead to eudaimonic growth. Although research on growth is growing, the relative lack of prospective research on personal growth is striking, particularly in the United States, where the self-made individual and personal growth are such dominant cultural ideals (McAdams, 2006). We hope that researchers will continue to differentiate varieties of personal growth and to study how the idea of growth helps shape self-identity, as these subjective phenomena can serve as indicators of how lives unfold, particularly with regard to eudaimonia.

\section{References}

Arnett, J. J. (2000). Emerging adulthood: A theory of development from the late teens through the twenties. American Psychologist, 55, 469480 . 
Baron, R. M., \& Kenny, D. A. (1986). The moderator-mediator variable distinction in social psychological research: Conceptual, strategic, and statistical considerations. Journal of Personality and Social Psychology, $51,1173-1182$.

Bauer, J. J. (2008). How the ego quiets as it grows: Ego development, growth stories, and eudaimonic personality development. In H. A. Wayment \& J. J. Bauer (Eds.), Transcending self-interest: Psychological explorations of the quiet ego (pp. 199-210). Washington, DC: American Psychological Association.

Bauer, J. J., \& McAdams, D. P. (2004a). Growth goals, maturity, and well-being. Developmental Psychology, 40, 114-127.

Bauer, J. J., \& McAdams, D. P. (2004b). Personal growth in adults' stories of life transitions. Journal of Personality, 72, 573-602.

Bauer, J. J., McAdams, D. P., \& Pals, J. L. (2008). Narrative identity and eudaimonic well-being. Journal of Happiness Studies, 9, 81-104.

Bauer, J. J., McAdams, D. P., \& Sakaeda, A. R. (2005a). Crystallization of desire and crystallization of discontent in narratives of life-changing decisions. Journal of Personality, 73, 1181-1213.

Bauer, J. J., McAdams, D. P., \& Sakaeda, A. R. (2005b). Interpreting the good life: Growth memories in the lives of mature, happy people. Journal of Personality and Social Psychology, 88, 203-217.

Bauer, J. J., \& Park, S. W. (in press). Growth isn't just for the young: Growth narratives, eudaimonic resilience, and the aging self. In P. S. Frye \& C. L. M. Keyes (Eds.), New frontiers in resilient aging: Life strengths and well-being in late life. Cambridge, England: Cambridge University Press.

Baumeister, R. F., \& Leary, M. R. (1995). The need to belong: Desire for interpersonal attachments as a fundamental human motivation. Psychological Bulletin, 117, 497-529.

Blagov, P. S., \& Singer, J. A. (2004). Four dimensions of self-defining memories (specificity, meaning, content, and affect) and their relationships to self-restraint, distress, and repressive defensiveness. Journal of Personality, 72, 481-511.

Bluck, S., \& Gluck, J. (2004). Making things better and learning a lesson: Experiencing wisdom across the lifespan. Journal of Personality, 72, 543-572.

Bursik, K. (1995). Gender-related personality traits and ego development: Differential patterns for men and women. Sex Roles, 32, 601-615.

Bursik, K., \& Martin, T. A. (2006). Ego development and adolescent academic achievement. Journal of Research on Adolescence, 16, 1-18.

Caspi, A., Roberts, B. W., \& Shiner, R. L. (2005). Personality development: Stability and change. Annual Review of Psychology, 56, 453-484.

Cohn, L. D. (1998). Age trends in personality development: A quantitative review. In P. M. Westenberg, A. Blasi, \& L. D. Cohn (Eds.), Personality development: Theoretical, empirical, and clinical investigations of Loevinger's conception of ego development (pp. 133-143). Mahwah, NJ: Erlbaum.

Deci, E. L., \& Ryan, R. M. (2000). The "what" and "why" of goal pursuits: Human needs and the self-determination of behavior. Psychological Inquiry, 11, 227-268.

Deci, E. L., \& Ryan, R. M. (2008). Hedonia, eudaimonia, and well-being: An introduction. Journal of Happiness Studies, 9, 1-11.

de Tocqueville, A. (1988). Democracy in America (J. P. Mayer, Ed., \& G. Lawrence, Trans.). New York, NY: Harper Perennial. (Original work published in 1840)

Diener, E., Emmons, R. A., Larson, R. J., \& Griffen, S. (1985). The Satisfaction With Life Scale. Journal of Personality Assessment, 49, 71-75.

Diener, E., Lucas, R. E., \& Scollon, C. N. (2006). Beyond the hedonic treadmill: Revising the adaptation theory of well-being. American Psychologist, 61, 305-314.

Erikson, E. H. (1968). Identity: Youth and crisis. New York, NY: Norton.

Flanagan, O. (2007). The really hard problem: Meaning in a material world. Cambridge, MA: MIT Press.
Hy, L. X., \& Loevinger, J. (1996). Measuring ego development (2nd ed.). Mahwah, NJ: Erlbaum.

John, O. P., \& Srivastava, S. (1999). The Big Five trait taxonomy: History, measurement, and theoretical perspectives. In L. A. Pervin \& O. P. John (Eds.), Handbook of personality: Theory and research (2nd ed., pp. 102-138). New York, NY: Guilford Press

Kamide, H., \& Daibo, I. (2008). Autobiographical memories and a good life: Eudaimonic and hedonic well-being of Japanese students. Manuscript submitted for publication.

Kashdan, T. B., Biswas-Diener, R., \& King, L. A. (2008). Reconsidering happiness: The costs of distinguishing between hedonics and eudaimonia. Journal of Positive Psychology, 3, 219-233.

Kasser, T., \& Ryan, R. M. (1993). A dark side of the American dream: Correlates of financial success as a central life aspiration. Journal of Personality and Social Psychology, 65, 410-422.

King, L. A., \& Hicks, J. A. (2007). Whatever happened to "what might have been"? Regrets, happiness, and maturity. American Psychologist, 62, 625-636.

King, L. A., \& Napa, C. K. (1998). What makes a life good? Journal of Personality and Social Psychology, 75, 156-165.

King, L. A., \& Noelle, S. S. (2005). Happy, mature, and gay: Intimacy, power, and difficult times in coming out stories. Journal of Research in Personality, 39, 278-298.

King, L. A., \& Raspin, C. (2004). Lost and found possible selves, subjective well-being, and ego development in divorced women. Journal of Personality, 72, 603-632.

King, L. A., Scollon, C. K., Ramsey, C., \& Williams, T. (2000). Stories of life transition: Subjective well-being and ego development in parents of children with Down Syndrome. Journal of Research in Personality, 34, $509-536$.

King, L. A., \& Smith, N. G. (2004). Gay and straight possible selves: Goals, identity, subjective well-being, and personality development. Journal of Personality, 72, 967-994.

Korda, M. (2001). Making the list: A cultural history of the American bestseller, 1900-1999. New York, NY: Barnes \& Noble.

Labouvie-Vief, G. (2006). Emerging structures of adult thought. In J. J. Arnett \& J. L. Tanner (Eds.), Emerging adults in America: Coming of age in the 21st century (pp. 59-84). Washington, DC: American Psychological Association.

Lodi-Smith, J., Geise, A. C., Roberts, B. W., \& Robins, R. W. (2009). Narrating personality change. Journal of Personality and Social Psychology, 96, 679-689.

Loevinger, J. (1976). Ego development. San Francisco, CA: Jossey-Bass.

Loevinger, J. (1993). Conformity and conscientiousness: One factor or two stages? In D. C. Funder, R. D. Parke, C. Tomlinson-Keasey, \& K Widaman (Eds.), Studying lives through time: Personality and development (pp. 189-206). Washington, DC: American Psychological Association.

Lyubomirsky, S., Sheldon, K. M., \& Schkade, D. (2005). Pursuing happiness: The architecture of sustainable change. Review of General Psychology, 9, 111-131.

Manners, J., Durkin, K., \& Nesdale, A. (2004). Promoting advanced ego development among adults. Journal of Adult Development, 11, 19-27.

Maslow, A. H. (1968). Toward a psychology of being. New York, NY: Van Nostrand Reinhold.

McAdams, D. P. (1988). Power, intimacy, and the life story: Personological inquiries into identity. New York, NY: Guilford Press.

McAdams, D. P. (1995). What do we know when we know a person? Journal of Personality, 63, 365-396.

McAdams, D. P. (2006). The redemptive self: Stories Americans live by. New York, NY: Oxford University Press.

McAdams, D. P., Bauer, J. J., Sakaeda, A. R., Anyidoho, N. A., Machado, M. A., Magrino-Failla, K., . . . Pals, J. L. (2006). Continuity and change 
in the life story: A longitudinal study of autobiographical memories in emerging adulthood. Journal of Personality, 74, 1372-1400.

McAdams, D. P., Hoffman, B. J., Mansfield, E. D., \& Day, R. (1996). Themes of agency and communion in significant autobiographical scenes. Journal of Personality, 64, 339-377.

McAdams, D. P., \& Pals, J. L. (2006). A new Big Five: Fundamental principles for an integrative science of personality. American Psychologist, 61, 204-217.

McCrae, R. R., \& Costa, P. T. (1999). A five-factor theory of personality. In L. A. Pervin \& O. P. John (Eds.), Handbook of personality: Theory and research (2nd ed., pp. 139-153. New York, NY: Guilford Press.

McLean, K. C. (2005). Late adolescent identity development: Narrative meaning making and memory telling. Developmental Psychology, 41, 683-691.

McLean, K. C., Pasupathi, M., \& Pals, J. L. (2007). Selves creating stories creating selves: A process model of self-development. Personality and Social Psychology Review, 11, 262-278.

McLean, K. C., \& Pratt, M. W. (2006). Life's little (and big) lessons: Identity statuses and meaning-making in the turning point narratives of emerging adults. Developmental Psychology, 42, 714-722.

Mroczek, D. K., \& Kolarz, C. M. (1998). The effect of age on positive and negative affect: A developmental perspective on happiness. Journal of Personality and Social Psychology, 75, 1333-1349.

Oishi, S., Diener, E., \& Lucas, R. E. (2007). The optimum level of well-being: Can people be too happy? Perspectives on Psychological Science, 2, 346-360.

Pals, J. L. (2006a). Constructing the "springboard effect": Causal connections, self-making, and growth within the life story. In D. P. McAdams, R. Josselson, \& A. Leibich (Eds.), Identity and story: Creating self in narrative (pp. 175-199). Washington, DC: American Psychological Association.

Pals, J. L. (2006b). Narrative identity processing of difficult life experiences: Pathways of personality development and positive selftransformation in adulthood. Journal of Personality, 74, 1079-1109.

Pasupathi, M., \& Mansour, E. (2006). Adult age differences in autobiographical reasoning in narratives. Developmental Psychology, 42, 798808

Roberts, B. W., O'Donnell, M., \& Robins, R. W. (2004). Goal and personality trait development in emerging adulthood. Journal of Personality and Social Psychology, 87, 541-550.
Ryan, R. M., \& Deci, E. L. (2001). On happiness and human potentials: A review of research on hedonic and eudaimonic well-being. Annual Review of Psychology, 52, 141-166.

Ryan, R. M., Huta, V., \& Deci, E. L. (2008). Living well: A selfdetermination theory perspective on eudaimonia. Journal of Happiness Studies, 9, 139-170.

Ryff, C. D., \& Singer, B. H. (2008). Know thyself and become what you are: A eudaimonic approach to psychological well-being. Journal of Happiness Studies, 9, 13-39.

Sheldon, K. M., \& Elliot, A. J. (1999). Goal striving, need satisfaction, and longitudinal well-being: The self-concordance model. Journal of Personality and Social Psychology, 76, 482-497.

Sheldon, K. M., \& Houser-Marko, L. (2001). Self-concordance, goal attainment, and the pursuit of happiness: Can there be an upward spiral? Journal of Personality and Social Psychology, 80, 152-165.

Sheldon, K. M., \& Kasser, T. (1995). Coherence and congruence: Two aspects of personality integration. Journal of Personality and Social Psychology, 68, 531-543.

Sheldon, K. M., Kasser, T., Smith, K., \& Share, T. (2002). Personal goals and psychological growth: Testing an intervention to enhance goal attainment and personality integration. Journal of Personality, 70, 5-31.

Sheldon, K. M., \& Lyubomirsky, S. (2006). Achieving sustainable gains in happiness: Change your actions, not your circumstances. Journal of Happiness Studies, 7, 55-86.

Truluck, J. E., \& Courtenay, B. C. (2002). Ego development and the influence of gender, age, and educational levels among older adults. Educational Gerontology, 28, 325-336.

Waterman, A. S., Schwartz, S. J., \& Conti, R. (2008). The implications of two conceptions of happiness (hedonic enjoyment and eudaimonia) for the understanding of intrinsic motivation. Journal of Happiness Studies, 9, 41-79.

Watson, D., Clark, L. A., \& Tellegen, A. (1988). Development and validation of brief measures of positive and negative affect: The PANAS Scales. Journal of Personality and Social Psychology, 54, 1063-1070.

Westenberg, P. M., \& Gjerde, P. F. (1999). Ego development during the transition from adolescence to young adulthood: A 9-year longitudinal study. Journal of Research in Personality, 33, 233-252.

Woike, B., Lavezzary, E., \& Barsky, J. (2001). The influence of implicit motives on memory processes. Journal of Personality and Social Psychology, 81, 935-945. 


\section{Appendix}

\section{Examples of Growth and Nongrowth Goals}

\section{Growth Goals}

Agentic intellectual-growth goal. "Coming to college, I met some very interesting people, many of whom have prompted me to question and develop my religious beliefs. Confronting questions of how I got here and why I am here on earth has made me very happy... . I want to never become so comfortable or narrowminded that I stop questioning my actions and beliefs."

Agentic and communal intellectual-growth goal. "I want to create art that causes people to think in new ways [and] which enriches people's lives. I write poetry and plays and am learning to write and think theatrically in school. I want to evoke societal change by reaching people personally and emotionally and intellectually through art."

Agentic socioemotional-growth goal (also communal, but only at the collective or societal level). "I want to make a difference in this world. . . I realize this sounds like a broad idea, but I believe I am capable of leaving this world a little better than I found it. Whether that means fighting for human rights, or the environment, or directing a charity organization, I want to make a difference in people's lives."

Agentic and communal socioemotional-growth goal. "Have a happy, healthy family. . . . To achieve this I will continue to live, grow, be true to myself, be open to new people. ... Then we will plan the best way to parent and run our household. Then we'll nurture our love and help it grow each day, as we raise our children."

\section{Nongrowth Goals}

- "I want to be the kind of husband/father that makes other people jealous. The one who always has well-behaved children who like him, and a loving wife. I guess it is sort of a storybook goal, but one I still strive for."

- "My second goal is to be known. I want people to know who I am. Not necessarily famous, but known. I want somebody to say my name and others recognize it."

- "Make a decent amount of money. No matter what I'd like to believe, I judge my worth by what I accomplish and I judge accomplishment by how much money I may one day make. Therefore, I want to make enough to have a nice house, nice clothes, nice car."

Received May 28, 2008

Revision received December 29, 2009

Accepted February 16, 2010 